OPEN ACCESS

Edited by: Kerri D. Seger, Applied Ocean Sciences, United States

Reviewed by:

Isha Bopardikar,

Indian Institute of Science Education and Research, Tirupati, India

Mario Barletta,

Federal University of Pernambuco,

Brazil

*Correspondence:

Oihane Fernandez-Betelu oihane.fernandez@abdn.ac.uk

tPresent address: Kate L. Brookes, Marine Laboratory, Marine Scotland Science, Aberdeen, United Kingdom

Specialty section: This article was submitted to Marine Ecosystem Ecology, a section of the journal Frontiers in Marine Science

Received: 04 February 2021 Accepted: 10 June 2021 Published: 12 July 2021

Citation:

Fernandez-Betelu O, Graham IM, Brookes KL, Cheney BJ, Barton TR and Thompson PM (2021) Far-Field Effects of Impulsive Noise on Coastal Bottlenose Dolphins.

Front. Mar. Sci. 8:664230 doi: 10.3389/fmars.2021.664230

\section{Far-Field Effects of Impulsive Noise on Coastal Bottlenose Dolphins}

\author{
Oihane Fernandez-Betelu*, Isla M. Graham, Kate L. Brookes ${ }^{\dagger}$, Barbara J. Cheney, \\ Tim R. Barton and Paul M. Thompson
}

Lighthouse Field Station, School of Biological Sciences, University of Aberdeen, Aberdeen, United Kingdom

Increasing levels of anthropogenic underwater noise have caused concern over their potential impacts on marine life. Offshore renewable energy developments and seismic exploration can produce impulsive noise which is especially hazardous for marine mammals because it can induce auditory damage at shorter distances and behavioral disturbance at longer distances. However, far-field effects of impulsive noise remain poorly understood, causing a high level of uncertainty when predicting the impacts of offshore energy developments on marine mammal populations. Here we used a 10-year dataset on the occurrence of coastal bottlenose dolphins over the period 2009-2019 to investigate far-field effects of impulsive noise from offshore activities undertaken in three different years. Activities included a 2D seismic survey and the pile installation at two offshore wind farms, $20-75 \mathrm{~km}$ from coastal waters known to be frequented by dolphins. We collected passive acoustic data in key coastal areas and used a Before-After Control-Impact design to investigate variation in dolphin detections in areas exposed to different levels of impulsive noise from these offshore activities. We compared dolphin detections at two temporal scales, comparing years and days with and without impulsive noise. Passive acoustic data confirmed that dolphins continued to use the impact area throughout each offshore activity period, but also provided evidence of short-term behavioral responses in this area. Unexpectedly, and only at the smallest temporal scale, a consistent increase in dolphin detections was observed at the impact sites during activities generating impulsive noise. We suggest that this increase in dolphin detections could be explained by changes in vocalization behavior. Marine mammal protection policies focus on the near-field effects of impulsive noise; however, our results emphasize the importance of investigating the far-field effects of anthropogenic disturbances to better understand the impacts of human activities on marine mammal populations.

Keywords: anthropogenic noise, $\mathrm{BACl}$, renewable energy, seismic exploration, acoustic disturbance, offshore wind farm, passive acoustic monitoring, marine mammal

\section{INTRODUCTION}

Ambient noise in the marine environment has increased since the 1950s due to the rise of human activities at sea (Frisk, 2012). In response to the heightened concerns about the potential impacts of noise on marine life, many countries have reached international agreements to monitor underwater noise levels (Van der Graaf et al., 2012; OSPAR, 2017; Reeve, 2019). In Europe, the Marine Strategy 
Framework Directive (MSFD) requires Member States to avoid sound sources that are likely to cause significant impact in the marine environment (Tasker et al., 2010). The MSFD sets out a series of indicators to assess the environmental status of an area, which for underwater noise is the proportion and spatial distribution of days on which sound sources exceed levels likely to entail significant impact.

Human activities such as pile-driving, seismic surveys and sonars produce some of the most powerful sounds underwater (Gordon et al., 2003). These impulsive sounds are defined as acute, broadband, transient signals with a rapid onset and a rapid decay ( $<1$ s) and are considered particularly hazardous to marine mammals (Southall et al., 2007). However, during the propagation, the acoustic characteristics of sound change at rates that vary according to the specific environmental conditions. The greatest change in the acoustic characteristics of impulsive sounds occurs within $\sim 10 \mathrm{~km}$ from the source (Hastie et al., 2019) and, therefore, the hazardous characteristics of these sounds will vary with distance (Southall et al., 2007). Impulsive sounds have the potential to impact cetaceans through direct injury at shorter distances (here near-field) and through behavioral disturbance at longer distances (here far-field; Erbe et al., 2018). Measures to mitigate near-field effects from injury are widely adopted (Bröker et al., 2015; Verfuss et al., 2016). However, potential far-field behavioral effects and the longer-term consequences of any shortterm disturbance remain challenging to assess (Pirotta et al., 2018). To date, most of the studies on the effect of impulsive noise on wild marine mammals have focused on harbor porpoises (Phocoena phocoena) and seals (Phoca vitulina) (e.g., Russell et al., 2016; Brandt et al., 2018; Graham et al., 2019). Other species, such as bottlenose dolphins (Tursiops truncatus), may react differently to this disturbance but information on this is sparse (David, 2006; Finneran et al., 2015; Graham et al., 2017). Due to the lack of empirical data, estimates of potential behavioral effects required for the regulation of marine energy developments have a high level of uncertainty for these animals (Merchant, 2019).

This uncertainty can be especially challenging where offshore energy developments are being considered within or near to areas used by protected cetacean populations. Over the last decade, three major energy developments have been undertaken in NE Scotland, near a Special Area of Conservation (SAC) that was established in the Moray Firth to protect bottlenose dolphins. These included a 2D seismic survey for oil and gas exploration in 2011, and the installation of foundation piles for two offshore wind farms in 2017 (Beatrice Offshore Wind Farm) and 2019 (Moray East Offshore Wind Farm), all of which are known to result in high levels of impulsive underwater noise (Madsen et al., 2006; Thomsen et al., 2011). The Habitats Directive (92/43/EEC) requires regulators to ensure that the Favorable Conservation Status of the SAC is maintained. Therefore, higher levels of assessment and protection were required prior to all three of these projects. The Appropriate Assessments undertaken by the regulator, concluded that there were no likely long-term impacts on the protected bottlenose dolphin population and permissions were granted (Berr, 2007; MS-LOT, 2014; MS-LOT and Marine Scotland Science, 2014). However, significant objections were raised during some of these processes, arguing that dolphins could be displaced from the southern coast of the Moray Firth, an important area for this population (Cheney et al., 2013).

Given the sensitivities surrounding this issue and the level of uncertainty in the predictions, we used passive acoustic monitoring (PAM) to investigate whether far-field effects of impulsive noise from these offshore activities resulted in displacement of dolphins from coastal waters in the southern Moray Firth. To do so, echolocation data loggers (CPODs) were deployed to study variation in dolphin detections in areas exposed to different levels of impulsive noise. First, year-toyear variability in dolphin occurrence was investigated in each of those areas. Second, Before-After Control-Impact analyses (BACI; Underwood, 1992; Smith, 2002) were performed at two temporal scales to assess potential differences in detections within these areas. At the medium temporal scale, the BACI analysis compared years in which impulsive noise from offshore activities was present or absent. At the small temporal scale, finer-scale patterns within years with offshore activity were explored by comparing days in which impulsive noise was present or absent. Lastly, during the construction of Moray East wind farm, a more extensive PAM array was deployed in the coastal area nearest this development to investigate whether dolphins were displaced away from it and toward the coast during piling days.

\section{MATERIALS AND METHODS}

\section{Study Area and Moray Firth Projects}

The study was carried out in the Moray Firth, a large triangular embayment of the North Sea that covers approximately 5,230 $\mathrm{km}^{2}$. The seabed gradually slopes from the coast to depths of up to $200 \mathrm{~m}$ and, in the center, there is a shallow sand bank of 40-50 m depth called the Smith Bank (Eleftheriou et al., 2004). The Firth is frequented by a range of cetacean species (Thompson et al., 2015; Robinson et al., 2017; Risch et al., 2019) that includes animals from a protected population of bottlenose dolphins that uses the Moray Firth SAC (Figure 1). The distribution of this population is primarily coastal (Thompson et al., 2015) and, although individuals show interannual variability in their range (Pirotta et al., 2015b), the population shows high site fidelity at a broader scale (Cheney et al., 2014). The area most intensively used by these dolphins is the inner Moray Firth, in the southwestern part of the Firth, which is considered to be their core area of distribution (Cheney et al., 2013). However, a large proportion of the population uses other areas further south along the east coast of Scotland, such as St Andrews Bay and the Tay Estuary (Arso Civil et al., 2019). The southern coast of the Moray Firth is also intensively used by these dolphins and acts as a corridor between the SAC in the Moray Firth and the other key areas around the east coast (Culloch and Robinson, 2008; Cheney et al., 2013; Arso Civil et al., 2019).

In 2011, between the 2nd and the 11th of September, 2D seismic surveys were undertaken within the central Moray Firth, at minimum distances of 18 and $42 \mathrm{~km}$ from the southern coast and inner Moray Firth, respectively (Figure 1 and Table 1). They were conducted with a 470 cubic inch airgun array and a 5-6 s 


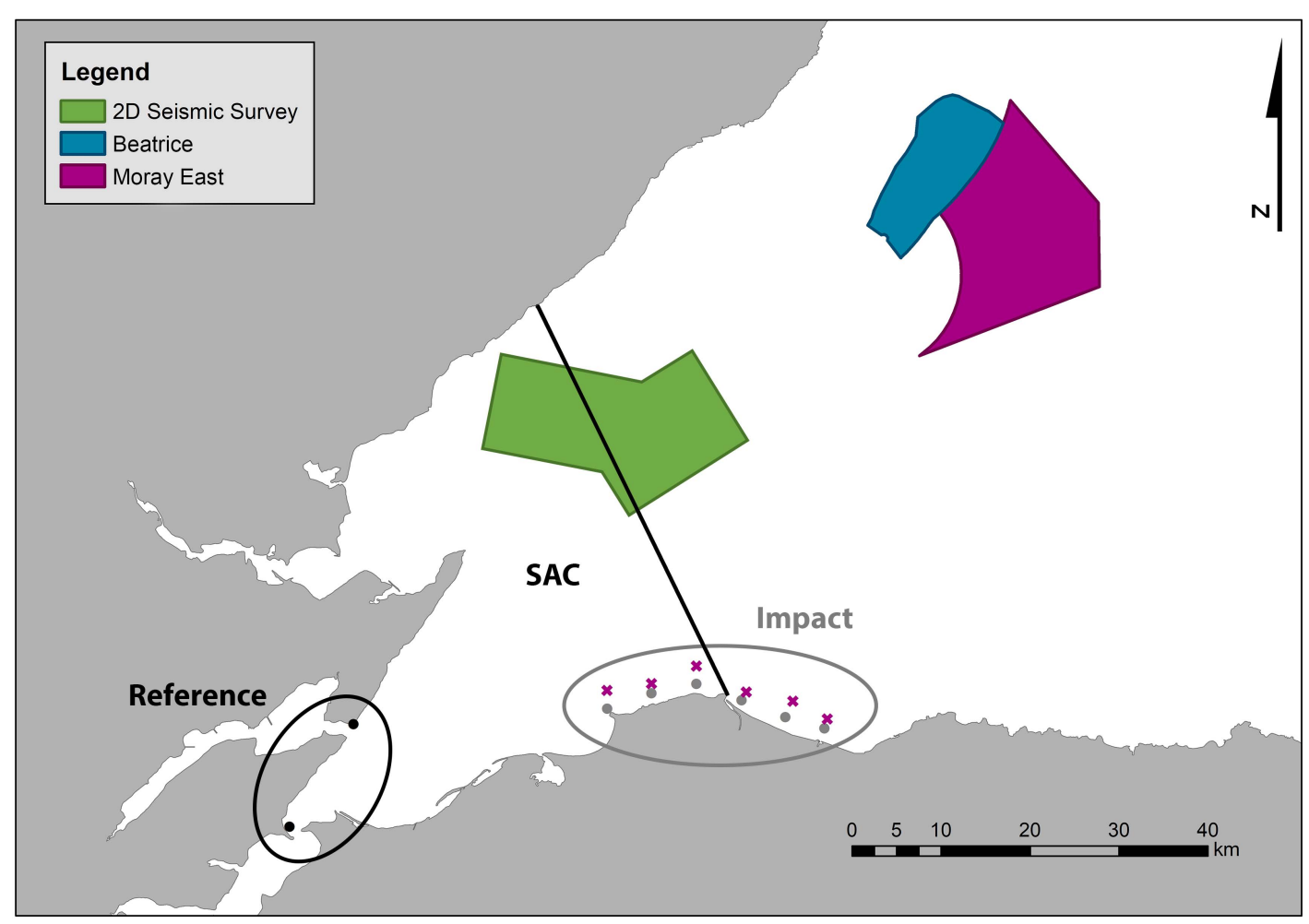

FIGURE 1 | Map of the Moray Firth showing the boundary of the Moray Firth SAC (solid line) and the areas in which different offshore projects were undertaken (2D seismic survey and Beatrice and Moray East wind farms). Circles (•): CPODs deployed from 2009 to 2019 (circled in black: Reference Area array; circled in gray: Impact Area array); X-shaped crosses (x): CPODs deployed in 2019 only (Impact Outer array).

shot interval (see Thompson et al., 2013 for survey details and modeled predictions of received noise levels). Between the 2nd April and the 2nd December 2017, the 344 pile foundations for the Beatrice wind farm were installed on the Smith Bank at least $53 \mathrm{~km}$ from the southern coast and $80 \mathrm{~km}$ from the inner Moray Firth. Each pile was hammered into the seabed using impulsive pile driving techniques with a maximum hammer energy of 2299 $\mathrm{kJ}$ (see Graham et al., 2019 for modeled predictions of received noise levels). On the 30th May 2019, construction started at the Moray East wind farm next to Beatrice; 264 pile foundations were installed between May and December 2019 (see MORL, 2016 for modeled predictions of received noise levels). Piles were installed using similar impulsive pile driving techniques and a maximum

TABLE 1 | Summary table with distance to the offshore project and maximum predicted received noise levels expressed as unweighted single-pulse sound exposure levels (SEL: dB re $1 \mu \mathrm{Pa}^{2}$ s (Thompson et al., 2013; MORL, 2016; Graham et al., 2019).

\begin{tabular}{lccc}
\hline & & Reference area & Impact area \\
\hline \multirow{2}{*}{ 2D seismic } & Minimum distance $(\mathrm{km})$ & 42 & 18 \\
& Max Received noise levels (SEL) & 132 & 139 \\
Beatrice & Minimum distance $(\mathrm{km})$ & 80 & 53 \\
& Max Received noise levels (SEL) & 100 & 128 \\
Moray east & Minimum distance (km) & 78 & 45 \\
& Max Received noise levels (SEL) & 93 & 141
\end{tabular}

hammer energy of $2071 \mathrm{~kJ}$ (see Supplementary Tables 1, 2 for detailed piling timelines from Beatrice and Moray East).

\section{Passive Acoustic Monitoring}

Echolocation detectors (CPODs, Chelonia Ltd.) were used to collect information on temporal patterns of occurrence in areas known to be frequented by bottlenose dolphins (Cheney et al., 2014). CPODs were deployed between 2009 and 2019 following previously described techniques (Bailey et al., 2010a; Thompson et al., 2013; Graham et al., 2019). Two CPODs were deployed at sites within the inner Moray Firth where the impact was expected to be lowest; hereafter the Reference Area (Figure 1; Fernandez-Betelu et al., 2019). These reference sites were located at minimum distances of 42,80 , and $78 \mathrm{~km}$ from the seismic survey, Beatrice and Moray East wind farm developments, respectively. Six CPODs were deployed along the southern Moray Firth coast, the part of the dolphin population's coastal range that was closest to all three offshore activities, where the impact was expected to be highest, hereafter the Impact Area (Thompson et al., 2010). These impact sites were located at minimum distances of 18,53 , and $45 \mathrm{~km}$ from the seismic survey, Beatrice and Moray East wind farm developments, respectively. In 2019, during the construction of Moray East wind farm, six extra CPODs were deployed in the Impact Area at greater distances from the coast (from 3 to $4 \mathrm{~km}$ ), hereafter Impact Outer area. With this array we aimed to investigate whether dolphins from 
further out at sea were displaced toward the coast in the southern Moray Firth by impulsive noise. Although data were collected year round at some locations, data from November to April were excluded from all the analyses due to the low occurrence of dolphins during those months along the southern Moray Firth coast (Fernandez-Betelu et al., 2019).

CPOD data were downloaded and trainfiltered using the manufacturer's software ${ }^{1}$ to identify which echolocation clicks were produced by dolphins. As recommended by the manufacturer, only click trains classified as high and moderate quality were used in this study. Since previous photo-ID, line transects and aerial surveys confirmed that the presence of other species of dolphins is rare in the studied sites (Thompson et al., 2015), all detected echolocation clicks were assumed to be produced by bottlenose dolphins. Detection Positive Hours per day (DPH) was the metric derived from the click train detections that we chose as the proxy for dolphin occurrence. $\mathrm{DPH}$ describes the number of hours in each day in which a dolphin click train was detected on each CPOD and is a robust proxy for studying odontocete occurrence (Brookes et al., 2013; Williamson et al., 2016). We used the statistical program R v. 3.5.1 (R Core Team, 2018) in all subsequent analyses.

\section{Inter-Annual Variability in Dolphin Occurrence}

Inter-annual variability in the occurrence of dolphins in the Reference and Impact Areas was characterized from a sub-set of comparable data from 4 long-term CPODs, two in each of the areas, that provided complete datasets for August and September from 2009 to 2019 (see timeline with CPOD deployments in Supplementary Figure 1). We calculated the DPH per day for these months and assessed the year-to-year variability in dolphin occurrence within these areas. Comparisons between years were made using non-parametric Kruskal-Wallis tests because data were not normally distributed.

\section{Far-Field Effects on Bottlenose Dolphin Occurrence in Relation to Seismic and Wind Farm Projects: Medium and Small Temporal Scales}

We performed BACI analyses (Underwood, 1992; Smith, 2002) to investigate whether there was a change in dolphin detections in the Impact Area relative to the more distant Reference Area during each offshore activity. In the BACI analyses we performed generalized linear mixed models (GLMM) with a Poisson family distribution and square root link function (Bolker et al., 2009). We used dolphin DPH as the response variable and included area (Reference Area/Impact Area) and period (Baseline period/Activity period) as fixed effects in interaction. At the medium temporal scale, the Activity period comprised years when offshore activities were undertaken and the Baseline period years without these offshore activities. At the small temporal scale, the Activity period included days in which impulsive noise was generated and the Baseline period, days in which impulsive noise

${ }^{1}$ www.chelonia.co.uk was not generated (Table 2). We included CPOD location and day within a year as random intercepts to remove patterns in the residuals and improve the fit of GLMM models at both temporal scales.

\section{Far-Field Effect on Bottlenose Dolphin Occurrence in Relation to Moray East Wind Farm: Displacement From the Southern Moray Firth at a Fine Spatial Scale}

During foundation installation at Moray East wind farm we investigated the occurrence of dolphins in the Impact Area at a fine spatial scale and assessed whether dolphins were displaced toward the coast during piling days. To do so, we assessed differences in dolphin DPH between the CPODs closer to the shore (Impact Inner array) and the CPODs further from the coast (Impact Outer array) in the impact area (Figure 1). We used GLMM and introduced array (Impact Inner/Impact Outer) and period (Piling/Non-piling days) as explanatory variables in interaction. CPOD location and day within a year were included as random intercepts.

\section{RESULTS}

CPODs were successfully deployed from 2009 to 2019 and provided more than 10,000 days of CPOD data. Gaps in the dataset occurred due to a combination of device failure and logistical constraints. Data from 2012 were removed from these analyses because only one CPOD was recovered that year from the Impact Area (Supplementary Figure 1).

TABLE 2 | Data used in the BACl analyses for the medium and small temporal scales.

\begin{tabular}{|c|c|c|c|c|}
\hline & & & Baseline period & Activity period \\
\hline \multirow{9}{*}{$\begin{array}{l}\text { Medium } \\
\text { temporal } \\
\text { scale }\end{array}$} & $2 \mathrm{D}$ & Dates & 01-14 Sep & 02-11 Sep \\
\hline & seismic & Years & 2009, 2010, 2013, 2014 & 2011 \\
\hline & & Tot. ndays & 60 & 10 \\
\hline & Beatrice & Dates & May-Sep & May-Sep \\
\hline & & Years & 2014, 2015, 2016, 2018 & 2017 \\
\hline & & Tot. ndays & 611 & 153 \\
\hline & Moray & Dates & May-Sep & May-Sep \\
\hline & East & Years & 2014, 2015, 2016, 2018 & 2019 \\
\hline & & Tot. ndays & 611 & 153 \\
\hline \multirow{9}{*}{$\begin{array}{l}\text { Small } \\
\text { temporal } \\
\text { scale }\end{array}$} & $2 \mathrm{D}$ & Dates & 23 Aug-01 Sep, 12-21 Sep & 02-11 Sep \\
\hline & seismic & Years & 2011 & 2011 \\
\hline & & Tot. ndays & 20 & $10(16.4 \%)$ \\
\hline & Beatrice & Dates & Non-piling days May-Sep & Piling days May-Sep \\
\hline & & Years & 2017 & 2017 \\
\hline & & Tot. ndays & 68 & 85 (52.4\%) \\
\hline & Moray & Dates & Non-piling days May-Sep & Piling days May-Sep \\
\hline & East & Years & 2019 & 2019 \\
\hline & & Tot. ndays & 101 & $52(24.6 \%)$ \\
\hline
\end{tabular}

Table includes the total number of days in each of the periods (Baseline period/Activity period) and the percentage of days with impulsive noise in August and September in brackets. 

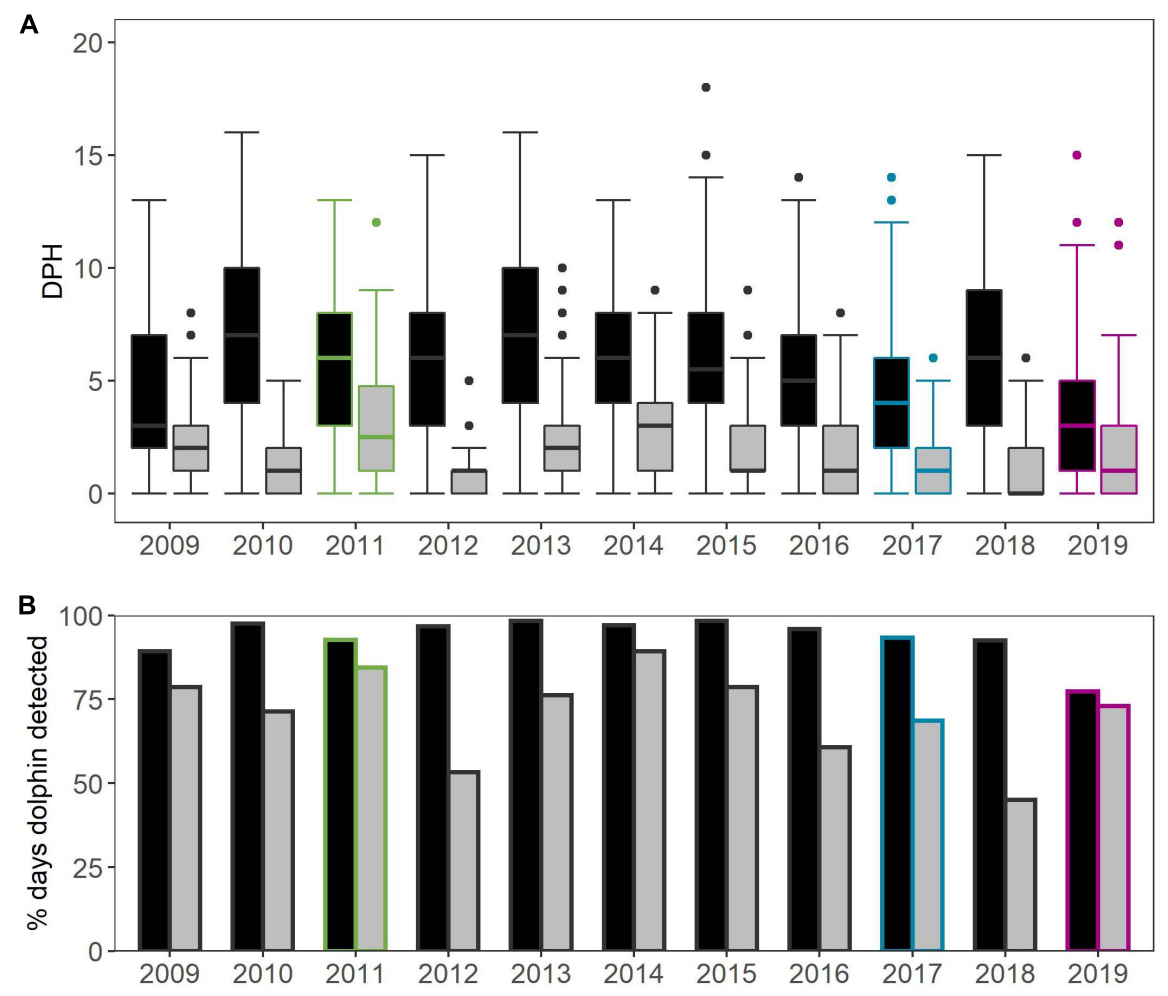

FIGURE 2 | Inter-annual variation in (A) dolphin Detection Positive Hours per day and (B) percentage of days that dolphins were detected in Reference Area (black) and Impact Area (gray). Data from August-September 2009 to 2019 from the 4 long-term CPODs. Colored borders indicate years when offshore activities took place (2011: 2D seismic survey; 2017: Beatrice wind farm construction; and 2019: Moray East wind farm construction).

\section{Inter-Annual Variability in Dolphin Occurrence}

The seismic survey, Beatrice and Moray East wind farm construction resulted in impulsive noise being produced within the Moray Firth on 16.4, 52.4, and 24.6\% of days in August and September 2011, 2017, and 2019, respectively (Table 2).

For the comparable subset of data from August-September, there were significant inter-annual differences in the daily occurrence of dolphins (DPH) in both areas (Figure 2A). The median DPH ranged between 3 and $7 \mathrm{~h}$ in the Reference Area $\left(X^{2}=102.26, \mathrm{df}=10, p<0.0001\right)$ and between 0 and $3 \mathrm{~h}$ in the Impact Area $\left(X^{2}=139.4, \mathrm{df}=10, p\right.$-value $\left.<0.0001\right)$ (Figure 3 and details in Supplementary Table 3). Dolphin detections were higher in the Reference Area than in the Impact Area during all years: dolphins were detected on $77-98 \%$ of the days in the Reference Area, compared to $45-89 \%$ of the days in the Impact Area (Figure 2B).

\section{Far-Field Effects on Bottlenose Dolphin Occurrence in Relation to Seismic and Wind Farm Projects: Medium and Small Temporal Scales}

At the medium temporal scale, the BACI analysis did not identify any consistent relationship between observed inter-annual variability and the occurrence of impulsive noise from these offshore activities (Figure 4 and Table 3 ). There were significant impacts of both the seismic survey and Beatrice wind farm construction, but the effects were in opposite directions. For the seismic survey in 2011, dolphin detections in the Impact Area increased by $50 \%$ (to a median of $3 \mathrm{~h}$ per day) compared to baseline years but reduced by $100 \%$ (to a median of $0.5 \mathrm{~h}$ per day) in the Reference Area (GLMM: $X^{2}=32.975$, $\mathrm{df}=1, p<0.001$ ). In contrast, during the Beatrice wind farm piling campaign in 2017, compared to baseline years, dolphin detections decreased by $50 \%$ in the Impact Area (to a median of $1 \mathrm{~h}$ per day) and decreased by $14 \%$ (to a median of $6 \mathrm{~h}$ per day) in the Reference Area (GLMM: $X^{2}=39.342$, $\mathrm{df}=1, p<0.001$ ). Finally, when impact piling was conducted at Moray East wind farm in 2019, no significant difference in dolphin detections between areas was found compared to baseline years (GLMM: $X^{2}=0.9451$, $\mathrm{df}=1$, $p>0.05$; Figure 4 and Table 3 ).

At the small temporal scale, the BACI analysis identified a significant impact of all three offshore activities, with an increase in dolphin detections in the impact area during those days on which impulsive noise was generated (Figure 5 and Table 3). For the seismic survey, an increase in dolphin detections of $200 \%$ (to a median of $3 \mathrm{~h}$ per day) was obtained in the Impact Area whereas a reduction of $90 \%$ (to a median of $0.5 \mathrm{~h}$ per day) was detected in the Reference Area (GLMM: $X^{2}=38.861$, df $=1, p<0.001$ ). 

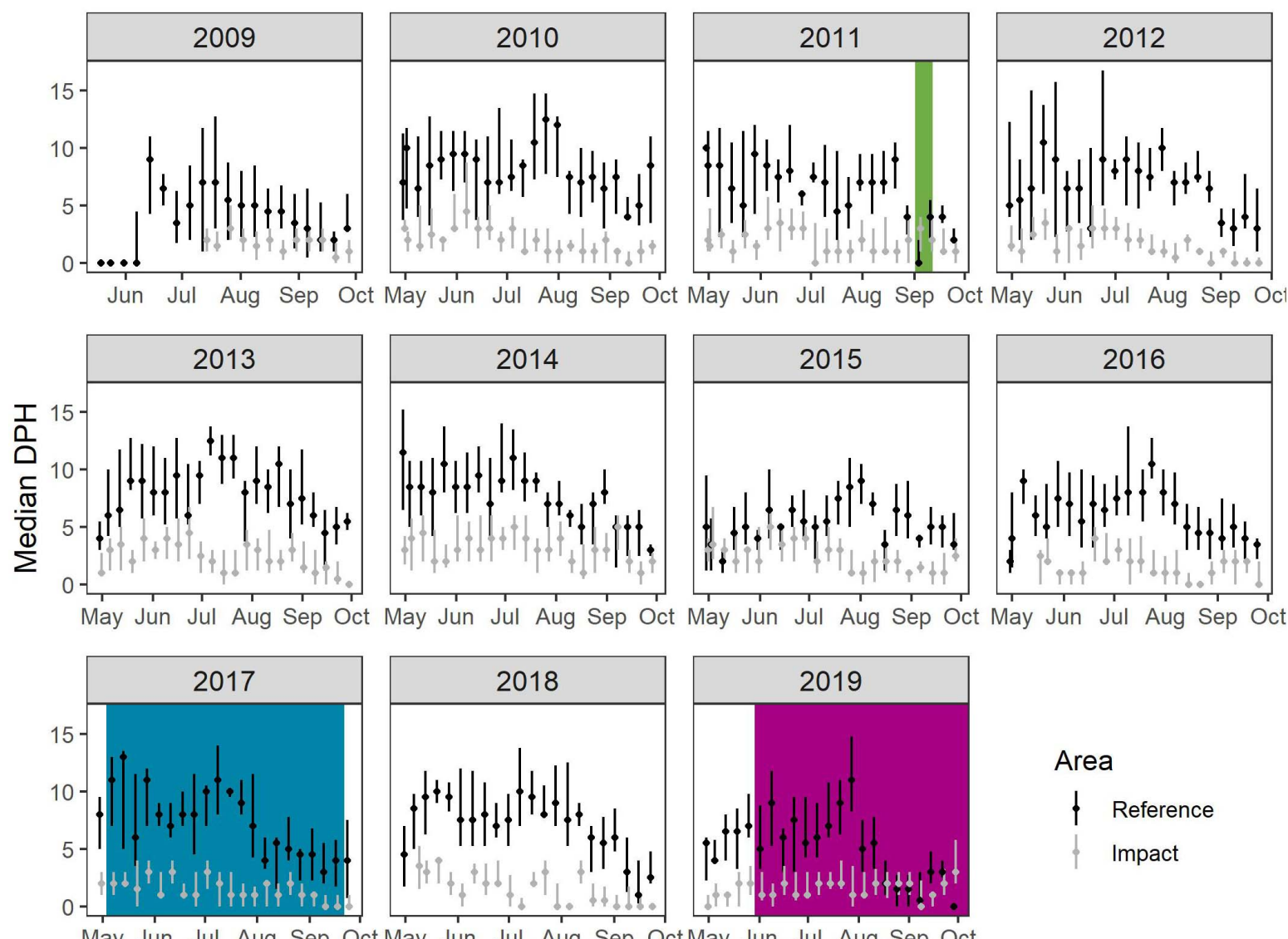

ct May Jun Jul Aug Sep Oct

May Jun Jul Aug Sep Oct May Jun Jul Aug Sep Oct May Jun Jul Aug Sep Oct

\section{Area \\ $\nmid$ Reference \\ Impact}

FIGURE 3 | Weekly median Detection Positive Hours (DPH) and inter-quartile ranges in the Reference Area (black) and Impact Area (gray) in each of the years studied. Colored areas indicate when offshore activities took place (green: 2D seismic survey; blue: Beatrice wind farm construction; magenta: Moray East wind farm construction).
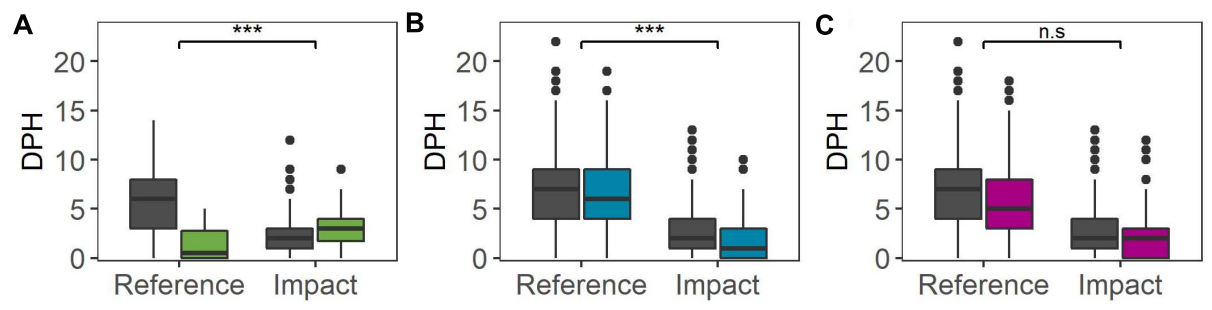

FIGURE 4 | Dolphin Detection Positive Hours (DPH) in the inner Moray Firth (Reference Area) and the southern Moray Firth (Impact Area) during the Baseline period (dark gray) and the Activity period (colored) at the medium temporal scale: (A) 2D seismic survey, (B) Beatrice wind farm construction and (C) Moray East wind farm construction. Significance of the interaction between period and area is indicated above the bar at the top: ${ }^{\star \star \star} P<0.001 ;$ n.s. $P>0.05$.

During pile-driving at Beatrice wind farm, an increase in dolphin detections of $100 \%$ was found in the Impact Area (to a median of $2 \mathrm{~h}$ per day) whereas there was no change in the Reference Area (GLMM: $X^{2}=5.198, \mathrm{df}=1, p<0.05$ ). For the Moray East wind farm development, dolphin detections increased by $100 \%$ (to a median of $2 \mathrm{~h}$ per day) in the Impact Area and increased by $20 \%$ (to a median of $6 \mathrm{~h}$ per day) in the Reference Area (GLMM: $X^{2}=4.807, \mathrm{df}=1, p<0.05$; Figure 5 and Table 3 ).

\section{Far-Field Effect on Bottlenose Dolphin Occurrence in Relation to Moray East Wind Farm: Displacement From the Southern Moray Firth at a Fine Spatial Scale}

There was a significant increase in dolphin detections during piling days in both Impact Inner and Impact 
TABLE 3 | Results of the Poisson generalized linear mixed models used to investigate the effect of impulsive noise from offshore activities on the acoustic detection of dolphins at sites in the inner Moray Firth (Reference Area) and the southern Moray Firth (Impact Area) at the medium and small temporal scales and in the Impact Inner and Impact Outer arrays at the fine spatial scale.

\begin{tabular}{|c|c|c|c|c|c|c|}
\hline & & & Estimate & Std. error & Df & $P$-Value \\
\hline \multirow{12}{*}{$\begin{array}{l}\text { Medium } \\
\text { temporal } \\
\text { scale }\end{array}$} & \multirow{4}{*}{$\begin{array}{l}\text { 2D seismic } \\
\text { survey }\end{array}$} & Intercept & 0.777 & 0.089 & 1 & $<0.001$ \\
\hline & & Period & 0.240 & 0.154 & 1 & 0.119 \\
\hline & & Area & 0.910 & 0.137 & 1 & $<0.001$ \\
\hline & & Period:Area & -1.617 & 0.286 & 1 & $<0.001$ \\
\hline & \multirow[t]{4}{*}{ Beatrice } & Intercept & 0.786 & 0.066 & 1 & $<0.001$ \\
\hline & & Period & -0.338 & 0.046 & 1 & $<0.001$ \\
\hline & & Area & 1.078 & 0.127 & 1 & $<0.001$ \\
\hline & & Period:Area & 0.270 & 0.041 & 1 & $<0.001$ \\
\hline & \multirow[t]{4}{*}{ Moray East } & Intercept & 0.786 & 0.069 & 1 & $<0.001$ \\
\hline & & Period & -0.205 & 0.046 & 1 & $<0.001$ \\
\hline & & Area & 1.085 & 0.132 & 1 & $<0.001$ \\
\hline & & Period:Area & 0.039 & 0.040 & 1 & 0.331 \\
\hline \multirow{12}{*}{$\begin{array}{l}\text { Small } \\
\text { temporal } \\
\text { scale }\end{array}$} & \multirow{4}{*}{$\begin{array}{l}\text { 2D seismic } \\
\text { survey }\end{array}$} & Intercept & 0.502 & 0.163 & 1 & 0.002 \\
\hline & & Period & 0.478 & 0.170 & 1 & 0.005 \\
\hline & & Area & 1.147 & 0.350 & 1 & 0.001 \\
\hline & & Period:Area & -0.186 & 0.298 & 1 & $<0.001$ \\
\hline & \multirow[t]{4}{*}{ Beatrice } & Intercept & 0.274 & 0.093 & 1 & 0.003 \\
\hline & & Period & 0.286 & 0.089 & 1 & 0.001 \\
\hline & & Area & 1.428 & 0.141 & 1 & $<0.001$ \\
\hline & & Period:Area & -0.174 & 0.077 & 1 & 0.023 \\
\hline & \multirow[t]{4}{*}{ Moray East } & Intercept & 0.385 & 0.121 & 1 & $<0.001$ \\
\hline & & Period & 0.327 & 0.086 & 1 & $<0.001$ \\
\hline & & Area & 1.209 & 0.208 & 1 & $<0.001$ \\
\hline & & Period:Area & -0.162 & 0.074 & 1 & 0.028 \\
\hline \multirow{4}{*}{$\begin{array}{l}\text { Fine spatial } \\
\text { scale }\end{array}$} & \multirow[t]{4}{*}{ Moray East } & Intercept & 0.471 & 0.397 & 1 & 0.235 \\
\hline & & Period & 0.245 & 0.082 & 1 & 0.003 \\
\hline & & Area & -2.211 & 0.603 & 1 & $<0.001$ \\
\hline & & Period:Area & 0.153 & 0.980 & 1 & 0.121 \\
\hline
\end{tabular}

Outer arrays compared to non-piling days (GLMM: $X^{2}=8.932, \mathrm{df}=1, p=0.003 ;$ Figure 6). Dolphin detections were significantly higher at the Impact Inner array than at the Impact Outer array (GLMM: $X^{2}=14.659$, $\mathrm{df}=1, p<0.001)$. The interaction between array and period was not significant (GLMM: $X^{2}=2.406$, $\mathrm{df}=1$, $p>0.05$; Table 3).

\section{DISCUSSION}

The analysis of 10 years of PAM data highlighted that dolphins used Moray Firth inshore areas regularly, albeit the extent of use varied from year to year without any consistent relationship to the impulsive noise generated by offshore activities. Nevertheless, at a fine temporal scale within offshore activity years, there was a significant change in dolphin occurrence depending upon the presence or absence of impulsive noise on different days.

The results of this study suggest that the impulsive noise generated by offshore activities did not cause any dolphin displacement from the southern coast of the Moray Firth. The southern coast is the closest area to the offshore activities within this bottlenose dolphin population's range (Arso Civil et al., 2019): the seismic survey took place $20-30 \mathrm{~km}$ away, and piling at Beatrice $50-70 \mathrm{~km}$ and Moray East $40-70 \mathrm{~km}$, from the southern coast. Predicted maximum received noise levels were $139 \mathrm{~dB}$ and $128 \mathrm{~dB}$ re $1 \mu \mathrm{Pa}^{2}$ s during the seismic survey and during piling at Beatrice wind farm, respectively (unweighted single pulse SEL; Thompson et al., 2013; Graham et al., 2019) and $141 \mathrm{~dB}$ re $\mu \mathrm{Pa}^{2} \mathrm{~s}$ in the worst-case scenario for Moray East wind farm (MORL, 2016). Our analyses showed that dolphins continued using the southern coast of the Moray Firth during the seismic survey and impact pile-driving. These results are in line with recent studies that found that displacement of marine mammals from impulsive noise sources only occurs at shorter distances. For instance, displacement of harbor porpoises and baleen whales, which are more sensitive to noise (Southall et al., 2019b), has been reported up to $20 \mathrm{~km}$ away from impulsive noise sources (Dähne et al., 2013; Dunlop et al., 2018; Graham et al., 2019; Southall et al., 2019a; Sarnocińska et al., 2020). There are no similar studies for bottlenose dolphins but, since they are less sensitive than baleen whales and harbor porpoises to noise, shorter ranges of displacement would be expected.

Contrary to expectations, the BACI analysis at the smaller temporal scale, showed an increase in dolphin detections on the southern Moray Firth coast on days with impulsive noise. Furthermore, this increase was consistent between all three offshore projects. The short-term increase in dolphin detections observed only at the smallest temporal scale is in line with
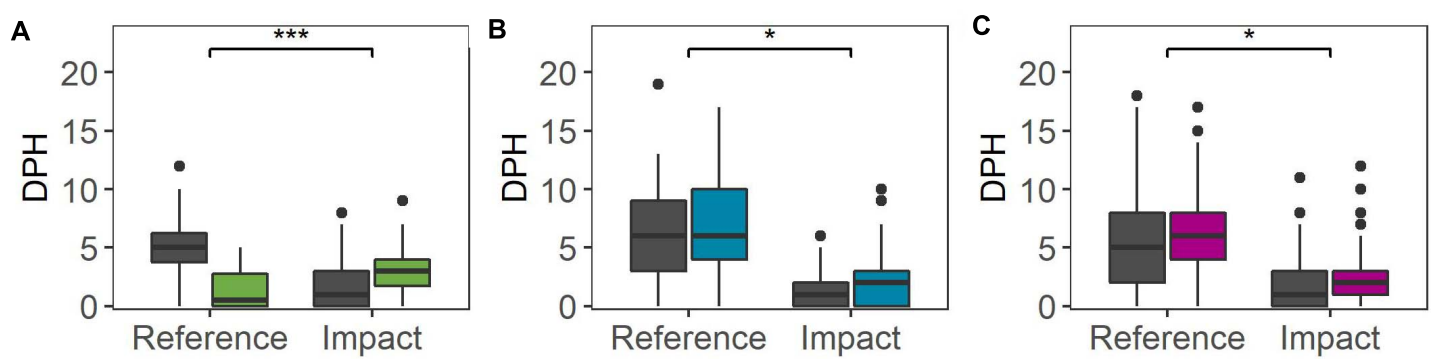

FIGURE 5 | Dolphin Detection Positive Hours (DPH) in the inner Moray Firth (Reference Area) and the southern Moray Firth (Impact Area) during the Baseline period (dark gray) and the Activity period (colored) on the small temporal scale: (A) 2D seismic survey, (B) Beatrice wind farm construction and (C) Moray East wind farm construction. Significance of the interaction between period and area is indicated above the bar at the top: ${ }^{\star \star \star} P<0.001 ;{ }^{\star} P<0.05$. 


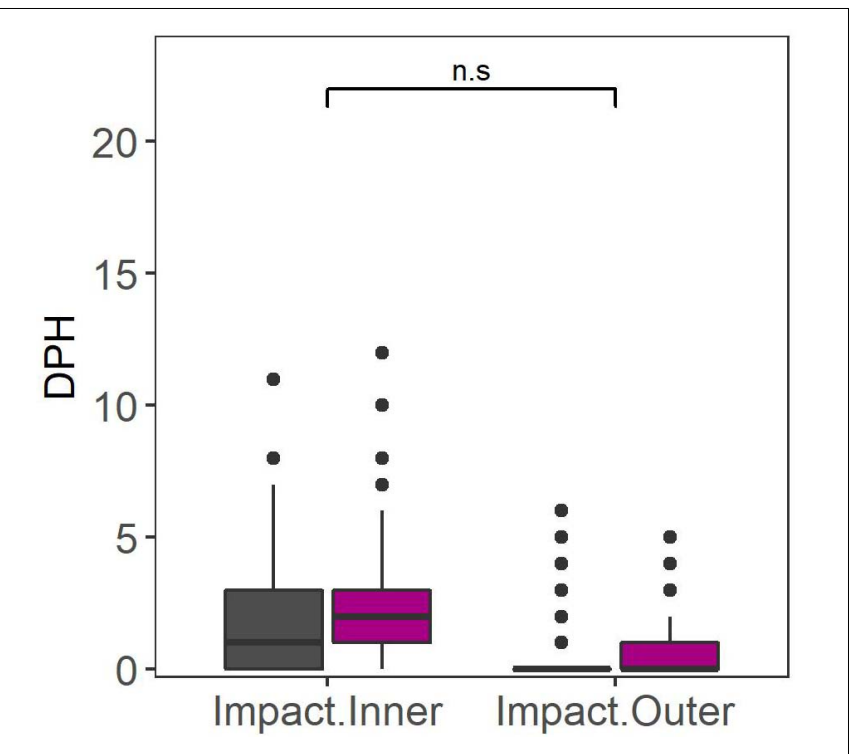

FIGURE 6 | Dolphin DPH for the Impact Inner and Impact Outer CPOD arrays in the Impact Area during the construction of Moray East wind farm (2019): non-piling days (dark gray) and piling-days (magenta). Significance of the interaction between period and array is indicated above the bar at the top: n.s. $P>0.05$.

previous studies that found that behavioral alterations due to noise exposure last less than a day (Thompson et al., 2013; Van Beest et al., 2018). Our findings are consistent with those of Bailey et al. (2010b) who, based on criteria in Southall et al. (2007) suggested that dolphins in this study area might exhibit modifications in behavior at around $50 \mathrm{~km}$ away from a piling vessel. Acute noises can modify marine mammal group size and group behavior (Visser et al., 2016; Curé et al., 2021), which in turn can cause changes in vocalizations (Henderson et al., 2012). Therefore, one possible explanation for the observed increase in dolphin detections is that noise modified bottlenose dolphin group sizes or group behavior. Although whistle vocalization rates have been linked to group sizes (Quick and Janik, 2008), echolocation click rates cannot be directly linked to the size of bottlenose dolphin groups (Nuuttila et al., 2013). Since our study was based on echolocation data loggers, we cannot test whether the increase in noise levels modified dolphin group sizes. Moreover, since CPOD detections and the number of individuals are not directly linked (Nuuttila et al., 2013), it does not follow that the increase in detections observed here is indicative of changes in group size. Changes in marine mammal vocalizations due to distant $(>20 \mathrm{~km})$ anthropogenic noise sources have been observed previously (Risch et al., 2012; Blackwell et al., 2013; Shannon et al., 2016). Therefore, another explanation of the increase in detections is that dolphins might have changed their vocalization rate (Blackwell et al., 2015) or the amplitude of their calls (Holt et al., 2009; Parks et al., 2011) in response to the impulsive noise generated by the offshore activities. In an experiment with captive bottlenose dolphins, the playback of pile driving noise resulted in an increase in the number of clicks produced by these animals (Branstetter et al., 2018). Caution is required when extrapolating information from trained to wild animals, but an increase in the click rate could explain the observed increase in detections by our CPODs during the impulsive noise events. Results obtained from the fine scale spatial analysis during the construction of Moray East wind farm also support this hypothesis. No displacement from the outer toward the inner array was observed during piling days, while a subtle but consistent increase in dolphin detections was observed on both arrays. Research is needed to further investigate potential changes in the acoustic characteristics of bottlenose dolphin clicks during far-field impulsive noise events. Passive acoustic devices that collect information on marine mammal click characteristics could be deployed during future offshore developments to explore in more detail whether these activities can be linked to differences in dolphin click rates or click amplitude.

At the medium temporal scale, comparing dolphin occurrence to baseline years, the results were not consistent between offshore activities. During the seismic survey, an increase in dolphin detections was observed on the southern coast. During the construction of Beatrice wind farm, a decrease was detected in the same area and during the construction of Moray East wind farm, no significant difference was detected. In line with previous studies, dolphin detections overall were higher in the Reference Area of the inner Moray Firth, compared with the Impact Inner area on the southern coast, but the extent of use varied between years and through the season (Thompson et al., 2015; FernandezBetelu et al., 2019). The difference in detections at the medium temporal scale therefore seems likely to be related to the natural inter-annual variation in occurrence that was also reflected in our analyses here (Figure 2). Although potentially modified by anthropogenic factors, bottlenose dolphin occurrence is largely influenced by a range of natural drivers, such as prey abundance and oceanographic processes (Heithaus and Dill, 2002; Benjamins et al., 2015). Our results suggest that the effect of far-field noise is less important than these other natural drivers in affecting the occurrence of dolphins in this study area.

We used a BACI design to investigate the effect of impulsive noise on the coastal occurrence of dolphins. This methodology is based on the comparison of data from two similar areas (Impact and Control) in situations where only one of them is affected by a disturbance. However, finding control sites with similar ecological characteristics to impact sites, while being distant enough to be unaffected by the disturbance, is not always feasible (Underwood, 1992, 1994). The sites defined here as reference sites were chosen because they were located at greater distances from the developments but were still within the bottlenose dolphin population's range. However, a complete lack of disturbance cannot be assured there, hence the term Reference instead of Control Area. For instance, during the construction of Moray East wind farm an increase in detections was observed at both Reference and Impact Areas during piling days, potentially indicating that noise levels might also have affected dolphins at reference sites. Nevertheless, these 10 years of passive acoustic 
monitoring data provided a robust dataset to investigate the effects of three offshore projects, while overcoming some of the limitations of the BACI design. The consistent results at the smallest temporal scale strengthened our hypothesis that a change in vocal behavior may have caused the observed increase in dolphin detections. While the contrasting results at the medium temporal scale from multiple offshore activities prevented us from suggesting misleading effects that might have been inferred from work conducted only during a single project. Overall, our analyses showed that long-term datasets such as this provide opportunities to detect relatively subtle differences in bottlenose dolphin behavior linked to the far-field impulsive noise generated by offshore activities.

\section{Management Implications}

Limited data on localized cetacean populations can constrain environmental assessments for new developments, particularly where these occur in or near protected areas. In the Moray Firth, concerns over the potential impacts of offshore developments on the protected population of bottlenose dolphins required additional research and survey effort in the area to inform licensing decisions.

The findings of this study support the Appropriate Assessments' conclusions that these offshore activities would not have a major impact on the bottlenose dolphin population using the SAC (Berr, 2007; MS-LOT, 2014; MS-LOT and Marine Scotland Science, 2014). Our results also concur with recent photo-ID studies of this dolphin population that showed increasing trends in both population size (Cheney et al., 2014) and vital rates (Cheney et al., 2019), supporting the lack of any large-scale impacts on the population. Our analysis showed that dolphins continued using the area of their range where the impact was expected to be highest when these projects took place. The monitoring of the farfield responses of dolphins provided evidence of potential short-term changes in vocalizations as reported for other marine mammal species (Gomez et al., 2016). Developers are required to perform marine mammal monitoring for several years to create a sufficient baseline and assess potential impacts (Diederichs et al., 2008). However, in places with high inter-annual variability in the presence of marine mammals, analyses using data from other years as a baseline may produce misleading results.

Marine mammal protection policies are focused on minimizing the near-field acute effects of impulsive noise (Bröker et al., 2015; Verfuss et al., 2016). While the risk of death or injury is limited to the first hundreds of meters from the sound source (Southall et al., 2019b), behavioral responses, such as changes in vocalizations, can occur at greater distances (hundreds of $\mathrm{km}$ ) potentially affecting a greater number of animals (Risch et al., 2012). Here, we suggested that distant impulsive noise sources may have caused modifications of bottlenose dolphin vocalizations. Further research is now required to test this hypothesis and describe the extent of any change in more detail, given that moderate modifications of vocal behavior have the potential to affect foraging and individual vital rates (Southall et al., 2007). The challenge in future research will be linking modifications of vocal behavior to changes in energetic costs (Booth, 2020; Pirotta et al., 2021) and, ultimately, population level consequences (Pirotta et al., 2015a; Reed et al., 2020).

\section{DATA AVAILABILITY STATEMENT}

All data are available from the Dryad Digital Repository. All datasets and $\mathrm{R}$ code used for the analyses are available at: https: //doi.org/10.5061/dryad.6hdr7sr17.

\section{ETHICS STATEMENT}

Ethical review and approval was not required for the animal study because this was a non-invasive, acoustic observational study of bottlenose dolphin responses to offshore seismic surveys and pile-driving. The authors had no control or influence over the duration or scheduling of offshore activities. No animals were captured or tagged during this study and no research or animal ethical assessments were required. Bottlenose dolphin responses to impulsive noise were determined using remote passive acoustic devices on seabed moorings licensed for scientific use by Marine Scotland, and consented by the Crown Estate. Moorings were deployed and recovered using vessels with appropriate certification, accreditation and endorsements.

\section{AUTHOR CONTRIBUTIONS}

OFB, IG, and PT designed the study based on data collection that had been led by IG, KB, and PT. TB managed data collection. IG and BC processed the raw data. All analyses were designed and conducted by OFB and supervised by IG. OFB led the writing of the manuscript. All authors reviewed and contributed critically to the drafts.

\section{FUNDING}

Financial support for this study was provided through a series of consortia funded projects that involved the UK Department of Energy and Climate Change (DECC), Scottish Government, Oil and Gas UK Ltd., COWRIE, NatureScot, The Crown Estate, Highlands and Islands Enterprise, Beatrice Offshore Wind Ltd., and Moray Offshore Wind Farm (East) Ltd. OFB was funded by the Fundación "la Caixa" (Becas Posgrado, 2015) and their support was greatly appreciated. The authors declare that this study received funding from three commercial developers: Oil and Gas UK Ltd., Beatrice Offshore Wind Ltd., and Moray Offshore Wind Farm (East) Ltd. However, these funding bodies had no input into the study design, data collection, analysis, interpretation of data, the writing of this article or the decision to submit it for publication. 


\section{ACKNOWLEDGMENTS}

We would like to thank Bill Ruck, Moray First Marine and colleagues from the University of Aberdeen for assistance with the data collection. We are also grateful to Drs. Nathan Merchant and Adrian Farcas (CEFAS) for the provision of the data on the noise modeling and their valuable comments during the development of this work. The project benefited at all stages from input provided by the scientific steering groups and stakeholder groups

\section{REFERENCES}

Arso Civil, M., Quick, N. J., Cheney, B., Pirotta, E., Thompson, P. M., and Hammond, P. S. (2019). Changing distribution of the east coast of Scotland bottlenose dolphin population and the challenges of area-based management. Aquat. Conserv. 29, 178-196. doi: 10.1002/aqc.3102

Bailey, H., Clay, G., Coates, E. A., Lusseau, D., Senior, B., and Thompson, P. M. (2010a). Using T-PODs to assess variations in the occurrence of coastal bottlenose dolphins and harbour porpoises. Aquat. Conserv. 20, 150-158. doi: $10.1002 / \mathrm{aqc}$

Bailey, H., Senior, B., Simmons, D., Rusin, J., Picken, G., and Thompson, P. M. (2010b). Assessing underwater noise levels during pile-driving at an offshore windfarm and its potential effects on marine mammals. Mar. Pollut. Bull. 60, 888-897. doi: 10.1016/j.marpolbul.2010.01.003

Benjamins, S., Dale, A., Hastie, G., Waggitt, J., Lea, M.-A., Scott, B., et al. (2015). "Confusion reigns? A review of marine megafauna interactions with tidal-stream environments," in Oceanography and Marine Biology: An Annual Review, eds R. N. Hughes, D. J. Hughes, I. P. Smith, and A. C. Dale (Boca Raton, FL: CRC Press), 1-54. doi: 10.1201/b18733-2

Berr (2007). Appropriate Assessment With Regard to 24th Offshore Oil and Gas Licensing Round (Inner Moray Firth). London: Berr.

Blackwell, S. B., Nations, C. S., McDonald, T. L., Greene, C. R., Thode, A. M., Guerra, M., et al. (2013). Effects of airgun sounds on bowhead whale calling rates in the Alaskan Beaufort Sea. Mar. Mamm. Sci. 29, E342-E365. doi: 10. $1111 / \mathrm{mms} .12001$

Blackwell, S. B., Nations, C. S., McDonald, T. L., Thode, A. M., Mathias, D., Kim, K. H., et al. (2015). Effects of airgun sounds on Bowhead whale calling rates: evidence for two behavioral thresholds. PLoS One 10:e0125720. doi: 10.1371/ journal.pone.0125720

Bolker, B. M., Brooks, M. E., Clark, C. J., Geange, S. W., Poulsen, J. R., Stevens, M. H. H., et al. (2009). Generalized linear mixed models: a practical guide for ecology and evolution. Trends Ecol. Evol. 24, 127-135. doi: 10.1016/j.tree.2008. 10.008

Booth, C. G. (2020). Food for thought: harbor porpoise foraging behavior and diet inform vulnerability to disturbance. Mar. Mamm. Sci. 36, 195-208. doi: $10.1111 / \mathrm{mms} .12632$

Brandt, M., Dragon, A., Diederichs, A., Bellmann, M., Wahl, V., Piper, W., et al. (2018). Disturbance of harbour porpoises during construction of the first seven offshore wind farms in Germany. Mar. Ecol. Prog. Ser. 596, 213-232. doi: 10. 3354/meps12560

Branstetter, B. K., Bowman, V. F., Houser, D. S., Tormey, M., Banks, P., Finneran, J. J., et al. (2018). Effects of vibratory pile driver noise on echolocation and vigilance in bottlenose dolphins (Tursiops truncatus). J. Acoust. Soc. Am. 143:429. doi: 10.1121/1.5021555

Bröker, K., Gailey, G., Muir, J., and Racca, R. (2015). Monitoring and impact mitigation during a $4 \mathrm{D}$ seismic survey near a population of gray whales off Sakhalin Island, Russia. Endanger. Species Res. 28, 187-208. doi: 10.3354/ esr00670

Brookes, K. L., Bailey, H., and Thompson, P. M. (2013). Predictions from harbor porpoise habitat association models are confirmed by long-term passive acoustic monitoring. J. Acoust. Soc. Am. 134, 2523-2533. doi: 10.1121/1. 4816577

Cheney, B., Corkrey, R., Durban, J. W., Grellier, K., Hammond, P. S., IslasVillanueva, V., et al. (2014). Long-term trends in the use of a protected area by established by UK and Scottish Governments to support the work conducted around these regional oil and gas and renewables projects.

\section{SUPPLEMENTARY MATERIAL}

The Supplementary Material for this article can be found online at: https://www.frontiersin.org/articles/10.3389/fmars. 2021.664230/full\#supplementary-material

small cetaceans in relation to changes in population status. Glob. Ecol. Conserv. 2, 118-128. doi: 10.1016/j.gecco.2014.08.010

Cheney, B. J., Thompson, P. M., and Cordes, L. S. (2019). Increasing trends in fecundity and calf survival of bottlenose dolphins in a marine protected area. Sci. Rep. 9:1767. doi: 10.1038/s41598-018-38278-9

Cheney, B., Thompson, P. M., Ingram, S. N., Hammond, P. S., Stevick, P. T., Durban, J. W., et al. (2013). Integrating multiple data sources to assess the distribution and abundance of bottlenose dolphins Tursiops truncatus in Scottish waters. Mamm. Rev. 43, 71-88. doi: 10.1111/j.1365-2907.2011. 00208.x

Culloch, R. M., and Robinson, K. P. (2008). Bottlenose dolphins using coastal regions adjacent to a special area of conservation in north-east Scotland. J. Mar. Biol. Assoc. U. K. 88, 1237-1243. doi: 10.1017/s0025315408000210

Curé, C., Isojunno, S., Siemensma, M. L., Wensveen, P. J., Buisson, C., Sivle, L. D., et al. (2021). Severity scoring of behavioral responses of sperm whales (Physeter macrocephalus) to novel continuous versus conventional pulsed active sonar. J. Mar. Sci. Eng. 9:444. doi: 10.3390/jmse9040444

Dähne, M., Gilles, A., Lucke, K., Peschko, V., Adler, S., Krügel, K., et al. (2013). Effects of pile-driving on harbour porpoises (Phocoena phocoena) at the first offshore wind farm in Germany. Environ. Res. Lett. 8:025002. doi: 10.1088/ 1748-9326/8/2/025002

David, J. A. (2006). Likely sensitivity of bottlenose dolphins to pile-driving noise. Water Environ. J. 20, 48-54. doi: 10.1111/j.1747-6593.2005.00023.x

Diederichs, A., Nehls, G., Dähne, M., Adler, S., Koschinski, S., and Verfuß, U. (2008). Methodologies for Measuring and Assessing Potential Changes in Marine Mammal Behaviour, Abundance or Distribution Arising from the Construction, Operation and Decommissioning of Offshore Windfarms. Husum: BioConsult SH Report to COWRIE Ltd.

Dunlop, R. A., Noad, M. J., McCauley, R. D., Kniest, E., Slade, R., Paton, D., et al. (2018). A behavioural dose-response model for migrating humpback whales and seismic air gun noise. Mar. Pollut. Bull. 133, 506-516. doi: 10.1016/j. marpolbul.2018.06.009

Eleftheriou, A., Basford, D., and Moore, D. C. (2004). Report for the Department of Trade and Industry - Synthesis of Information on the Benthos of Area SEA 5. Aberdeen.

Erbe, C., Dunlop, R., and Dolman, S. (2018). "Effects of noise on marine mammals," in Effects of Anthropogenic Noise on Animals, eds H. Slabbekoorn, R. J. Dooling, A. N. Popper, and R. R. Fay (New York, NY: Springer), 277-309.

Fernandez-Betelu, O., Graham, I. M., Cornulier, T., and Thompson, P. M. (2019). Fine scale spatial variability in the influence of environmental cycles on the occurrence of dolphins at coastal sites. Sci. Rep. 9:2548. doi: 10.1038/s41598019-38900-4

Finneran, J. J., Schlundt, C. E., Branstetter, B. K., Trickey, J. S., Bowman, V., and Jenkins, K. (2015). Effects of multiple impulses from a seismic air gun on bottlenose dolphin hearing and behavior. J. Acoust. Soc. Am. 137, 1634-1646. doi: 10.1121/1.4916591

Frisk, G. V. (2012). Noiseonomics: the relationship between ambient noise levels in the sea and global economic trends. Sci. Rep. 2:437. doi: 10.1038/srep00437

Gomez, C., Lawson, J. W., Wright, A. J., Buren, A. D., Tollit, D., and Lesage, V. (2016). A systematic review on the behavioural responses of wild marine mammals to noise: the disparity between science and policy. Can. J. Zool. 94, 801-819. doi: 10.1139/cjz-2016-0098 
Gordon, J. C. D., Gillespie, D., Potter, J., Frantzis, A., Simmonds, M. P., Swift, R., et al. (2003). A review of the effects of seismic survey on marine mammals. Mar. Technol. Soc. J. 37, 16-34. doi: 10.4031/002533203787536998

Graham, I. M., Merchant, N. D., Farcas, A., Barton, T. R., Cheney, B., Bono, S., et al. (2019). Harbour porpoise responses to pile-driving diminish over time. R. Soc. Open Sci. 6:190335. doi: 10.1098/rsos.190335

Graham, I. M., Pirotta, E., Merchant, N. D., Farcas, A., Barton, T. R., Cheney, B., et al. (2017). Responses of bottlenose dolphins and harbour porpoises to variations in piling noise during harbour construction. Ecosphere 8, $1-16$.

Hastie, G., Merchant, N. D., Götz, T., Russell, D. J. F., Thompson, P., and Janik, V. M. (2019). Effects of impulsive noise on marine mammals: investigating range-dependent risk. Ecol. Appl. 29:e01906. doi: 10.1002/eap.1906

Heithaus, M. R., and Dill, L. M. (2002). Food availability and tiger shark predation risk influence bottlenose dolphin habitat use. Ecology 83, 480-491. doi: 10.1890/ 0012-9658(2002)083[0480:faatsp]2.0.co;2

Henderson, E. E., Hildebrand, J. A., Smith, M. H., and Falcone, E. A. (2012). The behavioral context of common dolphin (Delphinus sp.) vocalizations. Mar. Mamm. Sci. 28, 439-460. doi: 10.1111/j.1748-7692.2011.00498.x

Holt, M. M., Noren, D. P., Veirs, V., Emmons, C. K., and Veirs, S. (2009). Speaking up: killer whales (Orcinus orca) increase their call amplitude in response to vessel noise. J. Acoust. Soc. Am. 125, EL27-EL32. doi: 10.1121/1.304 0028

Madsen, P. T., Wahlberg, M., Tougaard, J., Lucke, K., and Tyack, P. (2006). Wind turbine underwater noise and marine mammals: implications of current knowledge and data needs. Mar. Ecol. Prog. Ser. 309, 279-295. doi: 10.3354/ meps309279

Merchant, N. D. (2019). Underwater noise abatement: economic factors and policy options. Environ. Sci. Policy 92, 116-123. doi: 10.1016/j.envsci.2018.11.014

MORL (2016). Telford, Stevenson and MacColl Offshore Wind Farms - Piling Strategy. Outer Moray Firth: MORL.

MS-LOT, and Marine Scotland Science (2014). Appropriate Assessment for the Construction and Operation of the Beatrice Offshore Windfarm in the Outer Moray Firth. Aberdeen.

MS-LOT (2014). Appropriate Assessment for the Construction and Operation of Three Offshore Generating Stations - The Telford, Stevenson and Maccoll Offshore Wind Farms In The Outher Moray Firth. Aberdeen: MS-LOT.

Nuuttila, H. K., Thomas, L., Hiddink, J. G., Meier, R., Turner, J. R., Bennell, J. D., et al. (2013). Acoustic detection probability of bottlenose dolphins, Tursiops truncatus, with static acoustic dataloggers in Cardigan Bay, Wales. J. Acoust. Soc. Am. 134, 2596-2609. doi: 10.1121/1.4816586

OSPAR (2017). Distribution of Reported Impulsive Sounds [Online]. Available online at: https://oap.ospar.org/en/ospar-assessments/intermediateassessment-2017/pressures-human-activities/distribution-reportedimpulsive-sounds-sea/ (accessed August 17, 2020).

Parks, S. E., Johnson, M., Nowacek, D., and Tyack, P. L. (2011). Individual right whales call louder in increased environmental noise. Biol. Lett. 7, 33-35. doi: 10.1098/rsbl.2010.0451

Pirotta, E., Booth, C. G., Cade, D. E., Calambokidis, J., Costa, D. P., Fahlbusch, J. A., et al. (2021). Context-dependent variability in the predicted daily energetic costs of disturbance for blue whales. Conserv. Physiol. 9:coaa137. doi: 10.1093/ conphys/coaal37

Pirotta, E., Booth, C. G., Costa, D. P., Fleishman, E., Kraus, S. D., Lusseau, D., et al. (2018). Understanding the population consequences of disturbance. Ecol. Evol. 8, 9934-9946. doi: 10.1002/ece3.4458

Pirotta, E., Harwood, J., Thompson, P. M., New, L., Cheney, B., Arso, M., et al. (2015a). Predicting the effects of human developments on individual dolphins to understand potential long-term population consequences. Proc. R. Soc. B 282:20152109. doi: 10.1098/rspb.2015.2109

Pirotta, E., Thompson, P. M., Cheney, B., Donovan, C. R., and Lusseau, D. (2015b). Estimating spatial, temporal and individual variability in dolphin cumulative exposure to boat traffic using spatially explicit capture-recapture methods. Anim. Conserv. 18, 20-31. doi: 10.1111/acv.12132

Quick, N. J., and Janik, V. M. (2008). Whistle rates of wild bottlenose dolphins (Tursiops truncatus): influences of group size and behavior. J. Comp. Psychol. 122:305. doi: 10.1037/0735-7036.122.3.305

R Core Team (2018). R: A Language and Environment for Statistical Computing. Viena: R Core Team.
Reed, J., Harcourt, R., New, L., and Bilgmann, K. (2020). Extreme effects of extreme disturbances: a simulation approach to assess population specific responses. Front. Mar. Sci. 7:519845. doi: 10.3389/fmars.2020.519845

Reeve, L. L. N. (2019). "Transboundary pollution in the new legally binding instrument under the U.N. convention on the law of the sea: the case for anthropogenic underwater noise," in Proceedings of the Oceans 2019 MTS/IEEE Seattle (Piscataway, NJ: IEEE).

Risch, D., Corkeron, P. J., Ellison, W. T., and Van Parijs, S. M. (2012). Changes in humpback whale song occurrence in response to an acoustic source $200 \mathrm{~km}$ away. PLoS One 7:e29741. doi: 10.1371/journal.pone.0029741

Risch, D., Wilson, S. C., Hoogerwerf, M., van Geel, N. C. F., Edwards, E. W. J., and Brookes, K. L. (2019). Seasonal and diel acoustic presence of North Atlantic minke whales in the North Sea. Sci. Rep. 9:3571. doi: 10.1038/s41598-01939752-8

Robinson, K. P., Bamford, C. C. G., Airey, A., Bean, T. S., Bird, C., Haskins, G. N., et al. (2017). Killer whale (Orcinus orca) occurrence in the Moray Firth, Northeast Scotland: incidental sightings, behavioural observations, and photo-identification. Aquat. Mamm. 43, 26-32. doi: 10.1578/ AM.43.1.2017.26

Russell, D. J., Hastie, G. D., Thompson, D., Janik, V. M., Hammond, P. S., ScottHayward, L. A., et al. (2016). Avoidance of wind farms by harbour seals is limited to pile driving activities. J. Appl. Ecol. 53, 1642-1652. doi: 10.1111/13652664.12678

Sarnocińska, J., Teilmann, J., Balle, J. D., van Beest, F. M., Delefosse, M., and Tougaard, J. (2020). Harbor porpoise (Phocoena phocoena) reaction to a 3D seismic airgun survey in the North Sea. Front. Mar. Sci. 6:824. doi: 10.3389/ fmars.2019.00824

Shannon, G., McKenna, M. F., Angeloni, L. M., Crooks, K. R., Fristrup, K. M., Brown, E., et al. (2016). A synthesis of two decades of research documenting the effects of noise on wildlife. Biol. Rev. 91, 982-1005. doi: $10.1111 /$ brv. 12207

Smith, E. P. (2002). "BACI design," in Encyclopedia of Environmetrics, eds A. H. ElShaarawi and W. W. Piegorsch (Chichester: John Wiley \& Sons Ltd), 141-148.

Southall, B. L., Bowles, A. E., Ellison, W. T., Finneran, J. J., Gentry, R. L., Greene, C. R. Jr., et al. (2007). Marine mammal noise exposure criteria. Aquat. Mamm. 33:411.

Southall, B. L., Deruiter, S. L., Friedlaender, A., Stimpert, A. K., Goldbogen, J. A., Hazen, E., et al. (2019a). Behavioral responses of individual blue whales (Balaenoptera musculus) to mid-frequency military sonar. J. Exp. Biol. 222:jeb190637. doi: 10.1242/jeb.190637

Southall, B. L., Finneran, J. J., Reichmuth, C., Nachtigall, P. E., Ketten, D. R., Bowles, A. E., et al. (2019b). Marine mammal noise exposure criteria: updated scientific recommendations for residual hearing effects. Aquat. Mamm. 45, 125-232. doi: 10.1578/am.45.2.2019.125

Tasker, M. L., Amundin, M., Andre, M., Hawkins, A., Lang, W., Merck, T., et al. (2010). Marine Strategy Framework Directive Task Group 11 Report Underwater Noise and Other Forms of Energy. Copenhagen: ICES.

Thompson, P. M., Brookes, K. L., and Cordes, L. S. (2015). Integrating passive acoustic and visual data to model spatial patterns of occurrence in coastal dolphins. ICES J. Mar. Sci. 72, 651-660. doi: 10.1093/icesjms/fsu110

Thompson, P. M., Brookes, K. L., Graham, I. M., Barton, T. R., Needham, K., Bradbury, G., et al. (2013). Short-term disturbance by a commercial twodimensional seismic survey does not lead to long-term displacement of harbour porpoises. Proc. R. Soc. B 280:20132001. doi: 10.1098/rspb.2013.2001

Thompson, P. M., Lusseau, D., Barton, T., Simmons, D., Rusin, J., and Bailey, H. (2010). Assessing the responses of coastal cetaceans to the construction of offshore wind turbines. Mar. Pollut. Bull. 60, 1200-1208. doi: 10.1016/j. marpolbul.2010.03.030

Thomsen, F., McCully, S. R., Weiss, L. R., Wood, D. T., Warr, K. J., Barry, J., et al. (2011). Cetacean stock assessments in relation to exploration and production industry activity and other human pressures: review and data needs. Aquat. Mamm. 37, 1-93. doi: 10.1578/am.37.1.2011.1

Underwood, A. J. (1992). Beyond BACI: the detection of environmental impacts on populations in the real, but variable, world. J. Exp. Mar. Biol. Ecol. 161, 145-178. doi: 10.1016/0022-0981(92)90094-q

Underwood, A. J. (1994). On beyond BACI: sampling designs that might reliably detect environmental disturbances. Ecol. Appl. 4, 3-15. doi: 10.2307/ 1942110 
Van Beest, F. M., Teilmann, J., Hermannsen, L., Galatius, A., Mikkelsen, L., Sveegaard, S., et al. (2018). Fine-scale movement responses of free-ranging harbour porpoises to capture, tagging and short-term noise pulses from a single airgun. R. Soc. Open Sci. 5:170110. doi: 10.1098/rsos.170110

Van der Graaf, A. J., Ainslie, M. A., André, M., Brensing, K., Dalen, J., Dekeling, R. P. A., et al. (2012). European Marine Strategy Framework Directive-Good Environmental Status (MSFD GES): Report of the Technical Subgroup on Underwater Noise and Other Forms of Energy. Brussels: European Union.

Verfuss, U. K., Sparling, C. E., Arnot, C., Judd, A., and Coyle, M. (2016). "Review of offshore wind farm impact monitoring and mitigation with regard to marine mammals," in The Effects of Noise on Aquatic Life II, eds A. N. Popper and A. Hawkins (New York, NY: Springer), 1175-1182. doi: 10.1007/978-1-49392981-8_147

Visser, F., Curé, C., Kvadsheim, P. H., Lam, F.-P. A., Tyack, P. L., and Miller, P. J. O. (2016). Disturbance-specific social responses in long-finned pilot whales, Globicephala melas. Sci. Rep. 6:28641. doi: 10.1038/srep28641
Williamson, L., Brookes, K. L., Scott, B. E., Graham, I. M., Bradbury, G., Hammond, P. S., et al. (2016). Echolocation detections and digital video surveys provide reliable estimates of the relative density of harbour porpoises. Methods Ecol. Evol. 7, 762-769. doi: 10.1111/2041-210X.12538

Conflict of Interest: The authors declare that the research was conducted in the absence of any commercial or financial relationships that could be construed as a potential conflict of interest.

Copyright (c) 2021 Fernandez-Betelu, Graham, Brookes, Cheney, Barton and Thompson. This is an open-access article distributed under the terms of the Creative Commons Attribution License (CC BY). The use, distribution or reproduction in other forums is permitted, provided the original author(s) and the copyright owner(s) are credited and that the original publication in this journal is cited, in accordance with accepted academic practice. No use, distribution or reproduction is permitted which does not comply with these terms. 